\title{
Sibling cannibalism in dorada under experimental conditions. I. Ontogeny, dynamics, bioenergetics of cannibalism and prey size selectivity
}

\author{
E. Baras* $\|$, M. NdaO*†, M. Y. J. Maxi*†, D. JeAndrain*, J. P. Thomé ${ }^{*}$, \\ P. Vandewalle $\S$ and C. Mélard* \\ *Aquaculture Research and Education Centre, University of Liège, Belgium; $\dagger$ Institut \\ Sénégalais de Recherches Agronomiques, Centre de recherches océanographiques de \\ Dakar-Thiaroye (CRODTIISRA), Sénégal, \$Faculté d'Agronomie et de Médecine \\ Vétérinaire, Université d'Etat d'Haïti, Haïti, \Laboratory of Animal Ecology and \\ Ecotoxicology, University of Liège, Belgium and §Laboratory of Functional and \\ Evolutive Morphology, University of Liège, Belgium
}

(Received 30 December 1999, Accepted 25 May 2000)

\begin{abstract}
Cannibalism among sibling dorada Brycon moorei started before the yolk sac was completely absorbed, as soon as oral teeth were completely developed (1.2 mg fish, $21 \mathrm{~h}$ after hatching, $39 \mathrm{~h}$ after fertilization at $27 \cdot 0 \pm 0 \cdot 5^{\circ} \mathrm{C}$ under $12 \mathrm{~L}: 12 \mathrm{~N}$ ). Embryos attacked siblings of equivalent size or slightly larger than themselves, which were incompletely ingested, sucked up to the head and regurgitated (type Ia cannibalism). Two-day-old larvae performed complete ingestion but could not digest the head of their prey, which was regurgitated (type Ib cannibalism). One day later, all cannibals had turned to complete (type II) cannibalism. Type II cannibalism persisted during the larval period (ending $c .144 \mathrm{~h}$ after hatching, $26-38 \mathrm{mg}$ fish) and the early juvenile stage (15-30-g fish). The logistics of type II cannibalism (maximum prey to cannibal weight ratio, $W_{\mathrm{p}}: W_{\mathrm{C}}$ in percent) was modelled as $11.9607 W_{\mathrm{C}}^{-0.3429}\left(r^{2}=0.974, P<0.0001\right)$, where $W_{\mathrm{C}}$ is the body weight of the cannibal $(\mathrm{g})$, indicating that cannibals had to turn to increasingly smaller prey during their ontogeny. When being offered prey of different sizes, cannibals of all sizes $(0 \cdot 04-27 \mathrm{~g})$ preferred the smallest prey available almost systematically. A shortage of prey of appropriate size caused them to turn to larger prey, and eventually to exert incomplete cannibalism over siblings exceeding the maximum $W_{\mathrm{p}}: W_{\mathrm{C}}$ ratio. Cannibals could ingest extremely high food rations $\left[R_{\max }\left(\% W_{\mathrm{C}}\right)=47 \cdot 4242 W_{\mathrm{C}}^{-0.4002} ; r^{2}=0 \cdot 906, P=0 \cdot 0126\right]$, and showed extremely fast growth $\left(G\left[\%\right.\right.$ day $\left.^{-1}\right]=-2 \cdot 5895+0.5194 R-0.0007 R^{2} ; r^{2}=0.974$, $P<0 \cdot 0001)$. These traits caused cannibalism in dorada to be the earliest and most intense ever reported in fish (95-98\% fish cannibalized within the first week, of which $c .40 \%$ on the first day). The functional, adaptive and evolutionary implications of early predation and shifts between types of cannibalism in dorada are discussed. $\quad$ (C) 2000 The Fisheries Society of the British Isles
\end{abstract}

Key words: cannibalism; predation; evolution; adaptation; behaviour; Characidae.

\section{INTRODUCTION}

Since the time when it was regarded as a rare phenomenon or an experimental artefact, cannibalism has been reported in an increasing number of fish species (Smith \& Reay, 1991; Hecht \& Pienaar, 1993; Folkvord, 1997; Baras, 1998), and nowadays it is regarded as a key to population dynamics. Among the different types of cannibalism, intracohort sibling cannibalism is of particular importance

||Author to whom correspondence should be addressed. Present address: Aquaculture Research and Education Centre, 10 Chemin de la Justice, B-4500 Tihange, Belgium. Tel.: +32 852741 56; fax: + 32 852305 92; email: E.Baras@ulg.ac.be 
since preying on siblings is deemed to compromise the inclusive fitness of the cannibal (Jones, 1982; Dong \& Polis, 1992). Additionally, cannibalizing a large sibling includes a risk of retaliation, which is generally greater in predatory species (Polis, 1981; Brabrand, 1995). In spite of this, the highest impacts of cannibalism were reported precisely in predatory species (pike Esox lucius L., Bry \& Gillet, 1980; Giles et al., 1986; walleye Stizostedion vitreum Mitchill, Loadman et al., 1986; sea bass Dicentrarchus labrax L., Katavic et al., 1989; Eurasian perch Perca fluviatilis L., Mélard et al., 1996; syntheses in Smith \& Reay, 1991; Baras, 1998). Because cannibalism is mediated by appetite and metabolism, and is promoted by size differences, it is more intense among fast growing larvae and young juveniles than among older fish (Hecht \& Pienaar, 1993; Baras, 1998). Also, it emerges earlier, and is generally more intense in fast developing tropical species than in temperate ones.

Although data from tropical predatory fish species may lead to valuable models for the understanding of cannibalism, rarely have these species been studied in detail (snakehead Channa striatus Bloch, Qin \& Fast, 1996; sharptooth catfish Clarias gariepinus Burchell, Hecht \& Appelbaum, 1988; vundu catfish Heterobranchus longifilis Valenciennes; Baras, 1999). Fast developing predatory characids of the genus Brycon (sub-family Bryconinae) are potential models of extreme cannibalism in fish. Brycon spp. are widely spread all over Latin America, where they make long potamodromous migrations and contribute substantially to inland fisheries (Goulding, 1980). Their progressive decline in some river basins promoted the development of their aquaculture, but it is still compromised by a high mortality rate during the early development, due chiefly to cannibalism (e.g. matrinchá Brycon lundii Lütken in Brazil, Woynárovitch \& Woynárovitch, 1991; dorada B. moorei Steindachner in Colombia, E. Baras et al., unpubl. data).

The present study investigated the ontogeny of cannibalistic behaviour in dorada, focusing on the modes of prey capture and ingestion, logistics of cannibalism, prey size selectivity, food rations and impacts of cannibals at different developmental stages. Ways of mitigating cannibalism through zootechnical adjustments (feeding schedules, alternative prey and selection of progeny) are presented elsewhere (Baras et al., 2000).

\section{MATERIALS AND METHODS}

Juvenile siblings were obtained from the hormonally induced reproduction of captive breeders (after R. J. Otero, pers. comm.) in the Tihange Aquaculture Station of the University of Liège (Belgium). Eggs were incubated in Zuger jars at $27.0 \pm 0.5^{\circ} \mathrm{C}$, until hatching. The mean hatching time and delay was determined from samples of 100 individuals (eggs and hatched fish) collected at 30-min intervals. Until dorada had become juveniles, samples of fish were collected at regular intervals $(2-6 \mathrm{~h})$, weighed (nearest $0.1 \mathrm{mg}$ ) and examined under the dissection microscope to highlight the main steps of their morphological development (yolk sac resorption, gut opening, development of swimbladder, fins and finrays). Cannibalistic behaviour was described from 10-min samples at 2-h intervals during the embryonic and larval stages, then at 6-h intervals during the juvenile stage. On several occasions, cannibals and their prey were removed gently from the hatching tank, and placed in smaller enclosures for their continuous observation under the dissection microscope (magnification: $\times 4-40$ ). 
Experiments on the dynamics of cannibalism were conducted in three groups of sibling dorada, initially containing 250 fish aged $24 \mathrm{~h}$. Dorada were reared at $27 \cdot 0 \pm 0 \cdot 5^{\circ} \mathrm{C}$ under $12 \mathrm{~L}: 12 \mathrm{~N}$, with dissolved oxygen maintained at $c .6 \cdot 0 \mathrm{mg}^{-1}$ with an air diffuser. Live Artemia nauplii were distributed in excess six times a day, during daylight hours. The experimental enclosures consisted of small floating cages $(20 \times 12.5 \times 10 \mathrm{~cm})$ to shorten the emptying and daily monitoring procedures, and to minimize the trauma caused to fish. Fish were counted every day until the end of the experiment, the monitoring procedure never exceeding $5 \mathrm{~min}$ per enclosure. Dead fish were examined under the dissection microscope to determine the cause for their death. Fish heads or small tail-off dead fish were considered as victims of incomplete cannibalism, whereas missing fish were presumed to have succumbed to complete cannibalism. Fish with no missing body part but with obvious traces of bites were considered to have died from an unsuccessful cannibalistic attempt. Simultaneously, a large-scale validation experiment was conducted on six groups of 2000 1-day-old siblings each, originating from the same progeny, that were reared in larger floating cages (100 1), and examined after 1 week only. Day length, temperature, oxygen and food supply were identical as above.

Prey-size selectivity, and the relationships between ration ingested, growth and cannibal size were investigated chiefly in juvenile fish (i.e. fish with complete scale cover and finrays differentiated, that were deemed to exert complete cannibalism exclusively). Additional observations were made on larvae $(3-25 \mathrm{mg})$, involving the killing and dissection of the cannibal soon after it had ingested its prey, and weighing of cannibal and prey separately.

All experiments on juveniles had the same canvas, similar to that described in Baras (1999) and Baras et al. (1999). A single cannibal was placed in a 2.5-1 $(20 \times 12.5 \times 10 \mathrm{~cm})$ floating cage or $50-1$ aquarium at $27 \cdot 0 \pm 0.5^{\circ} \mathrm{C}$ under $12 \mathrm{~L}: 12 \mathrm{~N}$ (light: c. $50 \mathrm{~lx}$; night: c. $0.001 \mathrm{~lx}$ ), together with smaller siblings (potential prey). Cages and aquaria were part of a recirculating system where no food had ever been provided in order to avoid any involuntary flow of nutriment that could bias the measures of food consumption by cannibals. In addition, no food was distributed. All prey and cannibals were anaesthetized (2-phenoxy-ethanol, $0 \cdot 4 \mathrm{ml} \mathrm{l}^{-1}$ ) and weighed individually (nearest $0 \cdot 1 \mathrm{mg}$ ) just before the experiment. Prey were selected so that the cannibal could always find prey to be swallowed entirely on the first days of cannibalism, as well as prey too large to be cannibalized completely but not large enough to exert complete cannibalism upon other siblings. As in many other fish species (e.g. Atlantic cod Gadus morhua L.; Otterå \& Folkvord, 1993), dorada were expected to show allometric growth, and the prey to cannibal weight ratio $\left(W_{\mathrm{p}}: W_{\mathrm{C}}\right)$ was reduced progressively as fish age and size increased. The number of prey ranged from 15 to 21 , depending on their availability at the time of the experiments. Sixteen experiments were conducted on cannibals ranging from 0.02 to $28 \mathrm{~g}$ (Table I).

All experiments started at midday. Experiments on young larvae and juveniles $(0.008<$ prey $\leq 0.25 \mathrm{~g})$ did not extend over $>72 \mathrm{~h}$, as dorada were suspected to lose a substantial proportion of their body weight, and possibly to become lethargic after long starvation. Experiments on older juveniles $(0.096 \leq$ prey $\leq 2.0 \mathrm{~g})$ extended over an entire week. Every $24 \mathrm{~h}$, prey were counted, anaesthetized and weighed individually (nearest $0 \cdot 1 \mathrm{mg}$ ). The use of small cages permitted reduction of the emptying procedure to a few seconds, with no risk of injuring any fish. Anaesthesia and weight measurements never lasted $>30 \mathrm{~min}$ per series of experiments. All experimental fish recovered quickly ( $<1 \mathrm{~min}$ ) from anaesthesia and weighing, and showed no abnormal behaviour when they were placed back into the predation cages. These observations suggest that the monitoring procedure had little impact on the food consumption by cannibals and on health of prey. For each size range examined, a similar procedure was carried out on a control group, containing fish of size equivalent to the prey, and deemed to be unable to exert complete cannibalism on each other, in order to determine the negative growth rates of dorada of variable age starving over variable periods.

For each cage and day of experiment, the body weights of consumed prey were estimated using a two-step back-calculation process (inspired by Baras, 1999), relying on the primacy of early size differences, which is a valid assumption among starved fish: 
TABLE I. Synopsis of the experiments on complete cannibalism in juvenile dorada

\begin{tabular}{lrrrrr}
\hline Code & \multicolumn{2}{c}{ Cannibal } & Duration & \multicolumn{2}{c}{ Prey } \\
& $\begin{array}{c}W_{\mathrm{i}} \\
(\mathrm{mg})\end{array}$ & $\begin{array}{c}W_{\mathrm{f}} \\
(\mathrm{mg})\end{array}$ & $\begin{array}{c}\text { Nays) } \\
\text { (damber }\end{array}$ & $\begin{array}{c}W_{\mathrm{i}} \text { range } \\
(\mathrm{mg})\end{array}$ \\
\hline $\mathrm{A}$ & 22 & 62 & 2 & 15 & $3-23$ \\
$\mathrm{~B}$ & 40 & 161 & 4 & 19 & $17-36$ \\
$\mathrm{C}$ & 62 & 95 & 3 & 21 & $9-32$ \\
$\mathrm{D}$ & 75 & 160 & 4 & 20 & $8-27$ \\
$\mathrm{E}$ & 95 & 76 & 4 & 21 & $23-62$ \\
$\mathrm{~F}$ & 640 & 991 & 4 & 21 & $31-162$ \\
$\mathrm{G}$ & 640 & 829 & 4 & 21 & $32-162$ \\
$\mathrm{H}$ & 1075 & 1784 & 4 & 21 & $47-250$ \\
$\mathrm{I}$ & 1130 & 1872 & 4 & 21 & $55-222$ \\
$\mathrm{~J}$ & 6720 & 7606 & 7 & 20 & $105-634$ \\
$\mathrm{~K}$ & 6800 & 7865 & 7 & 20 & $100-736$ \\
$\mathrm{~L}$ & 8816 & 9531 & 7 & 20 & $115-703$ \\
$\mathrm{M}$ & 10882 & 11291 & 7 & 20 & $119-1271$ \\
$\mathrm{~N}$ & 14786 & 15131 & 7 & 20 & $193-1222$ \\
$\mathrm{O}$ & 22541 & 21255 & 5 & 18 & $170-1240$ \\
$\mathrm{P}$ & 28084 & 28013 & 7 & 20 & $292-1242$ \\
\hline
\end{tabular}

$W_{\mathrm{i}}$ and $W_{\mathrm{f}}$ are the initial and final body weights, respectively. All experiments at $27 \cdot 0 \pm 0 \cdot 5^{\circ} \mathrm{C}$ under 12L : $12 \mathrm{~N}$ (light: c. $50 \mathrm{~lx}$; night: c. $0.001 \mathrm{~lx}$ ). Experiments $\mathrm{A}$ to $\mathrm{I}$ and $\mathrm{J}$ to $\mathrm{P}$ in 2.5 and $50-1$ enclosures, respectively.

(i) calculation of the expected weight of prey after $24 \mathrm{~h}$ starving, based on the negative growth rate of starving prey measured in the control cage; and (ii) determination of the most probable distribution of surviving prey by successive iterations of missing cases (i.e. victims of cannibalism), and corresponding statistical comparisons (Pearson correlation) with the distribution of expected body weights. The $W_{\mathrm{p}}: W_{\mathrm{C}}$ ratios were calculated from body weights just before the act of cannibalism. The logistics of cannibalism was then modelled against fish body weight, using exclusively the highest $W_{\mathrm{p}}: W_{\mathrm{C}}$ ratios for cannibals of different body weights (i.e. single value for large individual cannibals, and several values for fast growing young cannibals).

The daily food ration $(R)$ of cannibals was obtained from the running sum of the body weights of siblings consumed in 1 day, and expressed as a proportion of the cannibal's initial body weight $\left(W_{\mathrm{C}}\right) . R$ was then compared (second order polynomial model) to the specific growth rate $\left(G, \%\right.$ day $\left.^{-1}\right)$ of cannibals, that was calculated as $G=100\left(\ln W_{\mathrm{Cf}^{-}}-\ln \right.$ $W_{\mathrm{Ci}}$ ), where $\mathrm{W}_{\mathrm{Cf}}$ and $\mathrm{W}_{\mathrm{Ci}}$ were the final and initial body weights of cannibals at 1-day intervals. Six complementary models were elaborated for six different body classes $(<0 \cdot 10,0 \cdot 10-0 \cdot 25,0 \cdot 6-2 \cdot 0,6-10,10-15$ and $>20 \mathrm{~g})$. Maintenance $\left(R_{\text {maint }}\right)$, optimum $\left(R_{\text {opt }}\right)$ and maximum $\left(R_{\text {max }}\right)$ rations (producing zero growth, best conversion efficiency and maximum growth, respectively) were deduced from these models, and tested against fish body weight, using power functions. The gross growth efficiency was calculated as the ratio between absolute growth $\left(G_{\mathrm{A}}\right)$ and daily food ration $(R)$. The net growth efficiency was calculated as $G_{\mathrm{A}}\left(R-R_{\text {maint }}\right)^{-1}$ (after Brett, 1979).

\section{RESULTS}

\section{ONTOGENY OF BRYCON MOOREI}

The following description synthesizes observations on three progenies spawned by different breeders and reared at identical temperatures and day 
lengths, and refers to non-cannibal fish only (see below). The timings varied slightly between progenies, by $<2 \%$ for hatching time, and by $<5 \%$ for the moment of metamorphosis.

Hatching started $17 \mathrm{~h} 20 \mathrm{~min}$ after fertilization, and all embryos hatched within the next $2 \mathrm{~h}$. Hereafter, the mean hatching time $(18 \mathrm{~h} 20 \mathrm{~min}$ after fertilization) is regarded as time 0 . Embryos were c. $3.7 \mathrm{~mm}$ long (total length), and averaged $0.4 \mathrm{mg}$. As early as $3 \mathrm{~h}$ after hatching, embryos were pelagic and showed a strong phototactic response (increased swimming under brighter light). The anus was opened at $c .5 \mathrm{~h}$ after hatching. The mouth started opening at $6 \mathrm{~h}$, and was completely open at $9 \mathrm{~h}$. Yolk sac resorption (YSR) was c. 35\% at this developmental stage (visual assessment). From 9 to $18 \mathrm{~h}$ after hatching, gape width increased progressively, and the cephalic region shifted progressively from a ventral to a terminal orientation. Oral teeth started developing at $c .12 \mathrm{~h}$, and $9 \mathrm{~h}$ later, they were completely developed as tiny daggers, differing strongly from the tricuspid structure documented in adults (Goulding, 1980). One-day-old embryos (YSR of $c .70 \%$ ) possessed differentiated pectoral fins, and averaged $6.0 \mathrm{~mm}$ and $1.2 \mathrm{mg}$. They were most active in the lower part of the water column, and exhibited a marked synchrony between heart rate, opercular beat rate and jaw movement (mean \pm S.D. $=101 \pm 8$ pulses min $^{-1}$ ).

The swimbladder was visible at $35 \mathrm{~h}$, and was fully developed as a unique pouch at $43 \mathrm{~h}$. At this developmental stage, eyes were highly mobile, YSR was always completed, and larvae occupied the entire water column, exhibiting ambush or hunting behaviour towards passing prey. Starving dorada, having exhausted their yolk reserves completely, died within $72-84 \mathrm{~h}$ after hatching. Finrays started developing $78 \mathrm{~h}$ after hatching, and were completely developed at 144-168 h [body weight $(W)$ 26-38 mg], except for pelvic fins that developed later (168-240 h, $W$ 40-125 mg). Two weeks after hatching ( $W 200-250 \mathrm{mg}$ ), dorada had absorbed their mid-ventral finfold, and were fully-developed juveniles, with tricuspid teeth.

Dorada feeding exclusively on siblings during their larval stage showed faster growth, and reached the juvenile stage within 8 days.

\section{ONTOGENY OF CANNIBALISTIC BEHAVIOUR}

Predation on small Artemia nauplii started as early as $18 \mathrm{~h}$ after hatching, whereas cannibalism did not start before the teeth were fully developed $(21 \mathrm{~h})$. Embryos of dorada were swimming randomly in the lower part of the water column, with a bite at each heart beat. Prey could be attacked head first or tail first (occurrences of 12.7 and $4 \cdot 2 \%$, respectively; 47 observations), but captures most frequently $(80.9 \%)$ took place after a lateral attack, with the predator grasping the caudal peduncle of its prey, then turning progressively to ingest its tail first [time elapsed between capture and start of ingestion: $74 \pm 9 \mathrm{~s}$ (mean \pm S.D.)]. The probability that a side- or tail-attacked prey escaped predation after having been held for more than $10 \mathrm{~s}$, was extremely low $(5 \cdot 3 \%)$, making this type of predation most efficient [Fig. 1(a)]. Prey were sucked in up to the head, which was eventually discarded 5-10 h after capture, depending on the proportion of prey effectively ingested (type Ia cannibalism). Cannibals with prey in their mouth were swimming erratically in the water column and frequently came in contact with other fish, which attacked them, thereby 

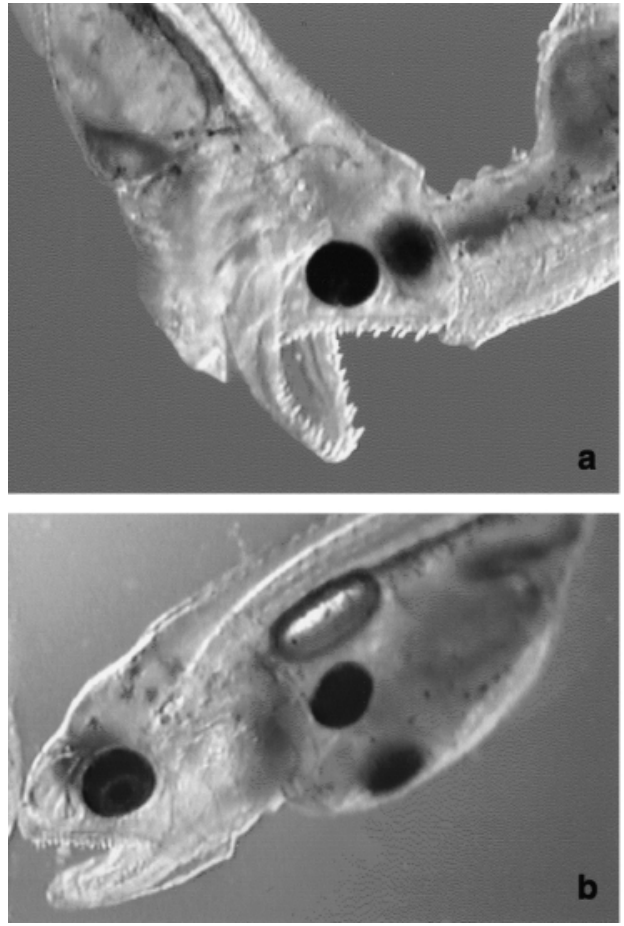
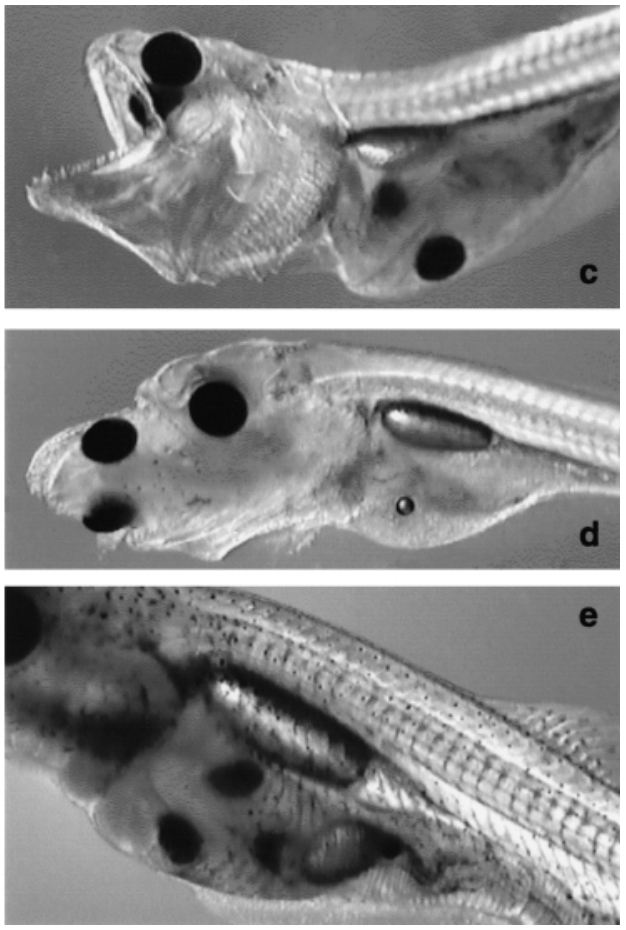

FIG. 1. Ontogeny of cannibalism in dorada. (a) Incomplete ingestion of a sibling by a 26-h-old, 1.2-mg embryo with an incompletely absorbed yolk sac (type Ia cannibalism). (b), (c), (d). Complete ingestion, then regurgitation of a sibling by a 46-h-old, $2 \cdot 8-\mathrm{mg}$ larva (type Ib cannibalism). The predator needs to expand its buccal cavity to its extreme limits for complete ingestion and prey regurgitation (c). Only the head of the prey is regurgitated, and its swimbladder, currently undergoing volume reduction during digestion, is visible in the predator's stomach (d). (e) Complete ingestion and digestion of a sibling by a 94-h-old, 10-mg larva.

promoting the formation of chains (c. $2 \cdot 1 \%$ of cannibalistic acts on the first day). Ingested prey remained alive for at least $30 \mathrm{~min}$ after ingestion had started. Because of the synchrony between heart rate and jaw movement, prey kept on biting during this period, and were occasionally observed capturing another prey at that time. This caused chains to get longer, exceptionally as long as seven individuals.

Until $27 \mathrm{~h}$ after hatching, all head attacks were unsuccessful. The cannibals were able to ingest the head of a prey of equivalent size, but it was blocked at the oesophagus, and regurgitated within seconds or minutes. After this, and probably because early cannibalism had promoted the emergence of size heterogeneity, cannibals were able to ingest their prey entirely within a few minutes, either after a head, tail or side attack [Fig. 1(b)]. However, the head of the prey was still regurgitated and eventually discarded $2-4 \mathrm{~h}$ after ingestion, while the remnants of the body were being digested [type Ib cannibalism; Fig. 1(c),(d)]. In larvae with fully developed swimbladders ( $\geq 43 \mathrm{~h})$, type Ib cannibalism had systematically replaced type Ia, and chains were no longer observed. Complete (type II) cannibalism was observed first at $48 \mathrm{~h}$, and was the only mode of predation exhibited by fish older than $72-78 \mathrm{~h}$ [Fig. 1(e)]. Type II 


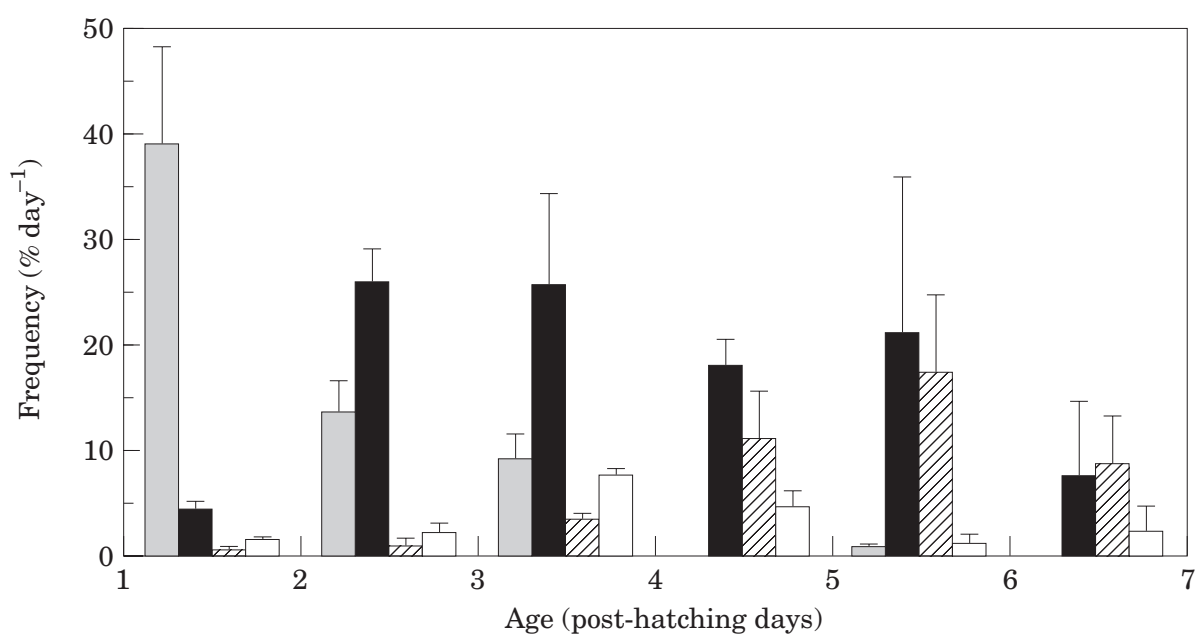

FIG. 2. Dynamics of sibling cannibalism among dorada. Type I (圆) and type II ( $\boldsymbol{\square}$ ) cannibalism refer to incomplete and complete prey consumption, respectively. Attacked fish ( $\square$ ) refer to fish dying of unsuccessful cannibalistic attempts. Daily rates are calculated as a proportion of the population surviving until the day before. Values and error bars are means and standard deviations of triplicates (three groups of 250 siblings each, reared over 6 days in $20 \times 12.5 \times 10 \mathrm{~cm}$ enclosures, at $27 \cdot 0 \pm 0 \cdot 5^{\circ} \mathrm{C}$ under $12 \mathrm{~L}: 12 \mathrm{~N}$, and fed to excess with Artemia nauplii). $\square$, Death due to other causes.

cannibalism persisted during the late larval and early juvenile stage, but its intensity decreased progressively, as the logistics of cannibalism became increasingly exigent (see below). An increasing number of attacked, but non ingested prey, preceded this decrease in cannibalism (Fig. 2). During the juvenile stage, type II cannibalism disappeared completely among fish of equivalent size. However, a new type of incomplete cannibalism (type III) was observed occasionally, when slightly smaller fish were attacked then cut into pieces progressively by most other siblings taking bites out of it, with just the head skeleton of the prey remaining intact. Aggression and type III cannibalism vanished in 15-30 g dorada (60 days after hatching), when their caudal peduncle acquired the typical black colour stripe and golden green colour exhibited by adults.

\section{IMPACT OF CANNIBALISM AT THE LARVAL AND JUVENILE STAGES}

Seven days after hatching, the survival of dorada in the three groups $(n=250)$ placed in small enclosures and examined at 24-h intervals, was extremely low (mean \pm S.D. $=2 \cdot 7 \pm 1 \cdot 8 \%$ ). From 24 to $48 \mathrm{~h}$ after hatching, up to $39 \cdot 1 \%$ of the population succumbed to type I ( $a$ and $b$ combined) cannibalism. The impact of type I cannibalism then decreased steeply and its occurrence was exceptional beyond day 4 . The impact of type II cannibalism peaked at $25 \cdot 9 \%$ day $^{-1}$ from day 2 to day 3, remained almost constant until day 6 , then decreased sharply after the proportion of unsuccessful attacks had increased up to $16 \cdot 4 \%$ day $^{-1}$. Mortality from causes other than cannibalism peaked in between day 3 and 4 , and corresponded mainly to death from starvation [small $(c .1 .0 \mathrm{mg})$ larvae with 


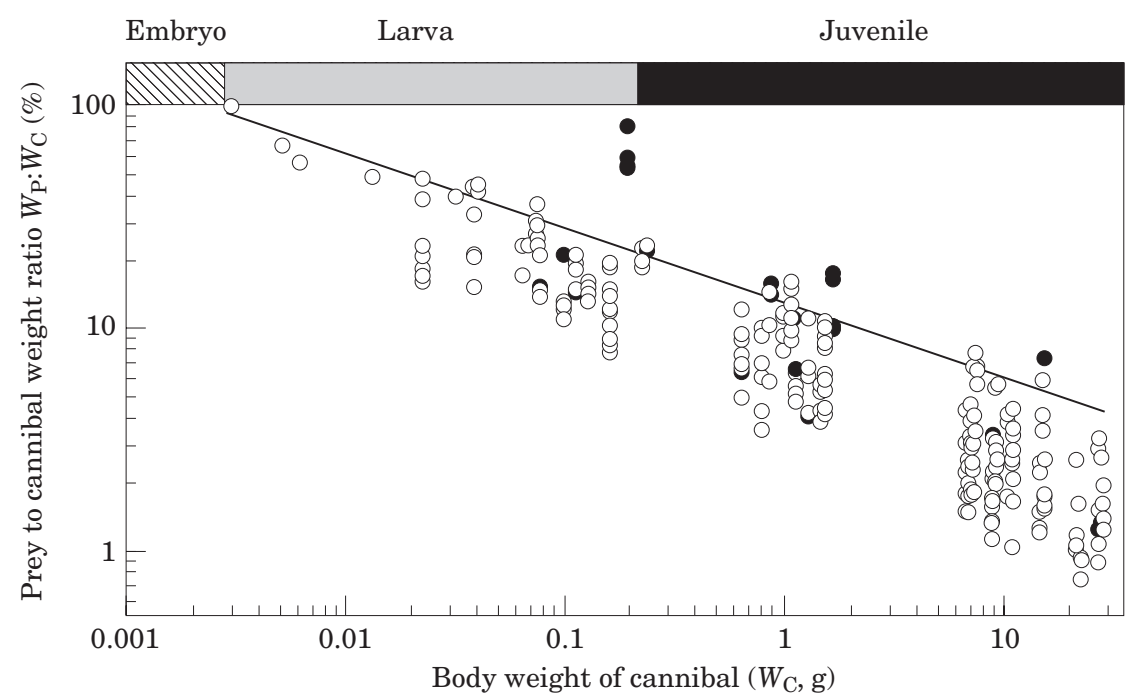

FIG. 3. Ontogenetic variation of the logistics of complete cannibalism in dorada. The model is obtained from the highest $W_{\mathrm{P}}: W_{\mathrm{C}}$ ratios of prey $(\mathrm{P})$ consumed by cannibals $(\mathrm{C})$ of different body weights. Complete $(\bigcirc)$ and incomplete $(\bigcirc)$ cannibalism. Values between brackets in the model are the standard errors of coefficients. Model $\left(r^{2}=0 \cdot 977\right.$, d.f. $\left.=20, P<0 \cdot 0001\right) ; W_{\mathrm{P}}: W_{\mathrm{C}}=11.9607(1 \cdot 0389)$ $W_{\mathrm{C}}^{-0 \cdot 3429(0 \cdot 0129)}$.

no gut content]. On average, cannibalism I and II eliminated directly $49 \cdot 1$ and $36 \cdot 2 \%$ of the initial population, and another $5 \cdot 5 \%$ died from unsuccessful cannibalistic attempts.

Similar low survival rates (mean \pm S.D. $=1 \cdot 5 \pm 0 \cdot 7 \%$ after 1 week of exogenous feeding) were observed in the six large enclosures containing initially 2000 siblings each, and examined only at the end of the larval period. This suggests that daily examinations and confinement in the groups described above did not interfere strongly with the genuine dynamics of cannibalism among dorada. The body weight of the 182 survivors ranged from 2 to $187 \mathrm{mg}$ (mean \pm S.D. $=29 \cdot 5 \pm 25.0 \mathrm{mg}$ ). During the next 100 days, an additional $163 \mathrm{fish}$ succumbed to cannibalism II and III, and only 16 fast growing fish survived $(0 \cdot 13 \%$ of the initial stock; $W$ of $59-169 \mathrm{~g})$.

\section{LOGISTICS OF CANNIBALISM AND PREY SIZE SELECTIVITY}

Type Ia cannibalism was not limited by the prey to cannibal weight ratio $\left(W_{\mathrm{P}}: W_{\mathrm{C}}\right)$, and on several occasions it was exerted upon prey slightly longer than the cannibal. Type Ib cannibalism could be analysed on four occasions only, when it was certain that the cannibal had started regurgitating a prey that had been completely swallowed. The $W_{\mathrm{P}}: W_{\mathrm{C}}$ ratios ranged from 76 to $96 \%$, suggesting that cannibals showing this behaviour could still ingest prey almost as large as themselves. Type II cannibalism could be analysed in 20 cannibals $(0 \cdot 005-27 \mathrm{~g})$ consuming 239 prey. The highest $W_{\mathrm{P}}: W_{\mathrm{C}}$ ratios decreased significantly during the larval and juvenile stages, from $66.7 \%$ in a $0.005 \mathrm{~g}$ larvae, to $3 \cdot 2 \%$ in a $27 \mathrm{~g}$ juvenile (Fig. 3). 
When being offered prey with a wide range of $W_{\mathrm{P}}: W_{\mathrm{C}}$ ratios, cannibals almost always consumed the smallest prey first, then turned progressively to prey of increasing size, as the smallest prey vanished (Fig. 4). This mode of prey size selectivity was observed consistently in all cannibals (0.02-27 g). Prey exceeding the logistics of cannibalism generally remained alive, but some $(n=11)$ were attacked and ingested incompletely by the cannibals. This observation confirms empirically the functional delimitation of the logistics of type II cannibalism, but indicates also that cannibals can shift occasionally to type I cannibalism consecutively to a shortage of prey of adequate size.

\section{FOOD RATIONS AND GROWTH OF CANNIBALS}

Due to the most restricted food intake of the largest cannibals examined $(>20 \mathrm{~g})$, the relationships between growth, ration and size in dorada were restricted to fish $\leq 15 \mathrm{~g}$. Cannibals of dorada showed extremely fast growth (Fig. 5), which was proportional to their food ration, and inversely proportional to their age and body weight (Table II, Fig. 6). Food ration decreased in fish of increasing size and age. In their late larval stage $(W<0 \cdot 2 \mathrm{~g})$, dorada could consume as much as $130 \cdot 2 \% \mathrm{~W}_{\text {day }^{-1}}$ and grew as fast as $52 \cdot 3 \% \mathrm{day}^{-1}$, whereas large (10-15 g) cannibals never consumed more than $13 \cdot 5 \% \mathrm{~W}$ day $^{-1}$ and did not grow faster than $5 \cdot 1 \%$ day $^{-1}$ (Fig. 5).

Predation experiments indicated that dorada needed extremely high maintenance rations (e.g. $8 \cdot 1 \% \mathrm{~W}_{\text {day }^{-1}}$ for a $0 \cdot 1 \mathrm{~g}$ fish), but these could be fulfilled through a single predation act on a sibling. High maintenance rations restricted the gross conversion efficiency proportionally to fish size (from $\leq 0.635$ in fish $<0.2$ g to $\leq 0.468$ in fish $>6 \mathrm{~g}$ ), whereas the net growth efficiency (taking into account the food ration needed for maintenance, calculated from the model in Table II) did not vary substantially between fish of different ages and sizes (maxima of 0.801 in fish $<0.2 \mathrm{~g}$ and 0.732 in fish $\geq 6 \mathrm{~g}$ ).

Contrary to the maintenance and optimum food rations, the maximum daily rations derived from the models presented in Fig. 5 should be considered with caution since no single cannibal dorada was observed ingesting such rations in the present experiments. Therefore, it is suggested that the maximum rations consumed effectively by cannibals of different size be used as a more realistic estimate of the actual ingestion capacities of dorada (Table II).

\section{MODELLING THE MAXIMUM IMPACT OF A CANNIBAL ON SIBLINGS}

The models above were used to estimate the impact of a single cannibal dorada on siblings, starting from the growth curve of a cannibal weighed at regular intervals from the larval stage (Fig. 6). Daily food rations consumed by the cannibal were deduced from the $G$ against $R$ model given in Table II, and the maximum $W_{\mathrm{P}}: W_{\mathrm{C}}$ was calculated from the logistics of cannibalism in dorada (Fig. 2). Assuming the cannibal eats the largest possible prey, the ratio between these values gives the minimum number of prey consumed each day, which amounts to 61 prey over 20 days. Because cannibal dorada prefer smaller prey (mean of all experiments: $53.95 \%$ of the logistics), the number of prey consumed over 20 days would reach 113. Based on the models illustrated in Fig. 6, it is obvious that the potential impact of an individual cannibal increases during its growth. As a corollary, the decreasing impact of cannibalism during the 

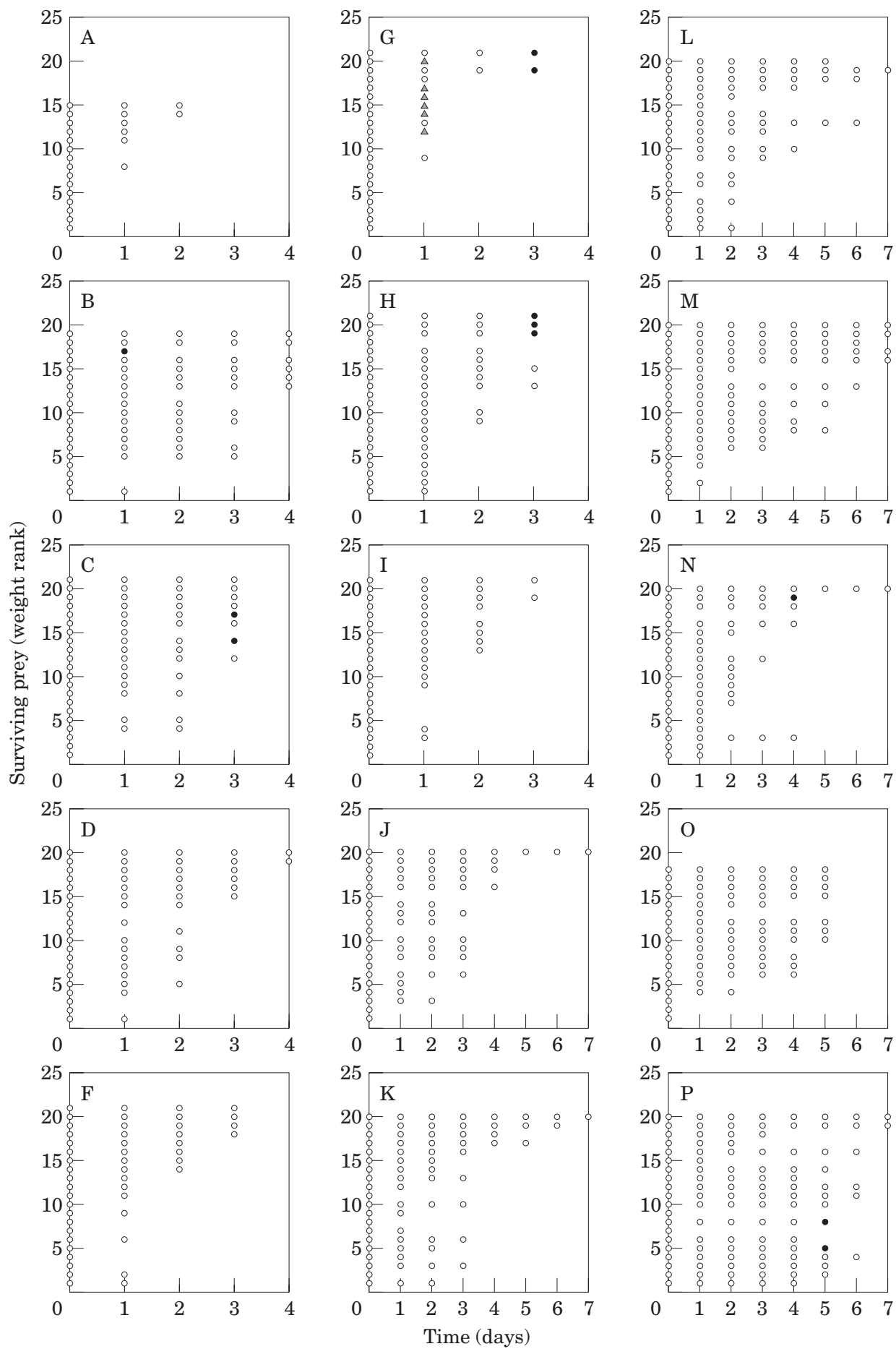

FIG. 4. Prey size selectivity in juvenile dorada. Codes $\mathrm{A}$ to $\mathrm{P}$ correspond to the situations described in Table I. Prey are ranked in increasing body weight ( 1 is the smallest fish). $\bigcirc$, Surviving fish. Missing cases along a horizontal line indicate that the fish has succumbed to complete (type II) cannibalism. - Prey remnants indicating that the fish has succumbed to incomplete (type I) cannibalism. A $(G)$ Probable victims of cannibal H, that leapt into enclosure $G$ soon after the experiment started and was unnoticed until the next day. Cannibal $\mathrm{E}$ ate no prey and is not illustrated. 

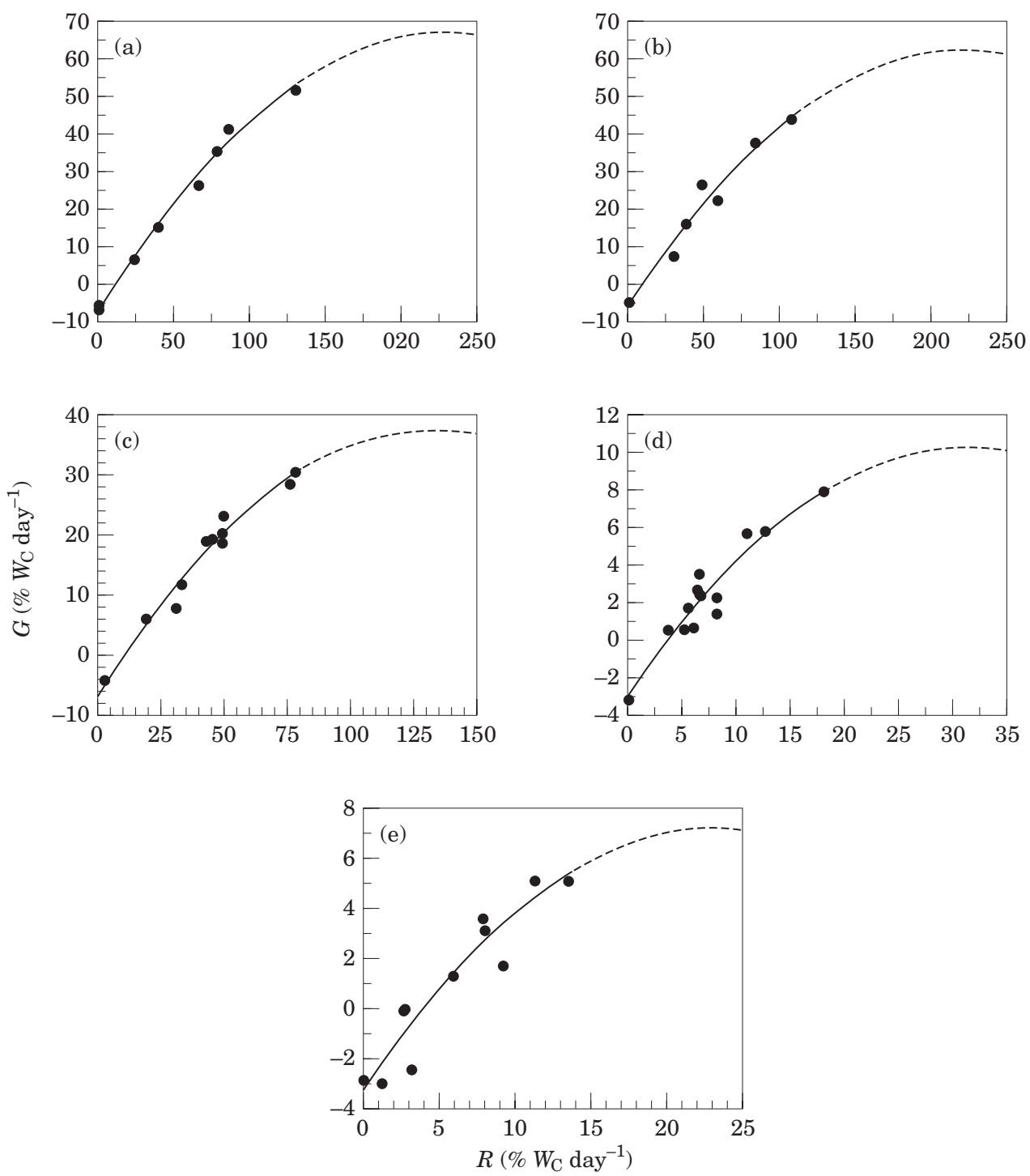

FIG. 5. Relationships between specific growth rate $(G)$ and daily food ration $(R)$ of juvenile cannibals of dorada of different body weights $\left(W_{\mathrm{C}}\right)$. (a) $0.04-0.08 \mathrm{~g}$; (b) $0.10-0.16 \mathrm{~g}$; (c) $0.64-1.55 \mathrm{~g}$; (d) $6 \cdot 8-9 \cdot 3 \mathrm{~g}$; (e) $10 \cdot 8-15 \cdot 5 \mathrm{~g}$. Due to low food consumption and weight loss in cannibals $\mathrm{O}$ and $\mathrm{P}$ (Table I), no model was calculated for 20-30 g juveniles. Values between brackets in the models are the standard errors of coefficients. (a) Model $\left(r^{2}=0.992 ;\right.$ d.f. $\left.=8, P<0.0001\right)$; $G=-6 \cdot 415(1 \cdot 278)+0 \cdot 641(0 \cdot 054) R-0 \cdot 001391(0 \cdot 00044) R^{2} . \quad$ (b) $\quad\left(r^{2}=0.961 ; \quad\right.$ d.f. $\left.=6, \quad P=0 \cdot 0015\right)$; $G=-5 \cdot 173(3 \cdot 861)+0 \cdot 617(0 \cdot 151) R-0 \cdot 001396(0 \cdot 001296) R^{2} . \quad$ (c) $r^{2}=0 \cdot 969 ; \quad$ d.f. $\left.=10, \quad P<0 \cdot 001\right)$; $G=-6 \cdot 183(2 \cdot 006)+0 \cdot 665(0 \cdot 095) R-0 \cdot 002527(0 \cdot 001069) R^{2}$. (d) $\left(r^{2}=0 \cdot 896\right.$, d.f. $\left.=14, P<0 \cdot 0001\right)$; $G=-2 \cdot 896(0 \cdot 792)+0 \cdot 840(0 \cdot 178) R-0 \cdot 01333(0 \cdot 00898) R^{2} . \quad\left(\right.$ e) $\quad\left(r^{2}=0 \cdot 889, \quad\right.$ d.f. $\left.=10, \quad P=0 \cdot 0002\right)$; $G=-3 \cdot 213(0 \cdot 794)+0 \cdot 892(0 \cdot 293) R-0 \cdot 019106(0 \cdot 021608) R^{2}$.

ontogeny of dorada is mediated chiefly by a decrease in the number of individuals that can exert cannibalism as accessible prey vanish progressively, and not by a decrease of the potential impact of individual fish. 


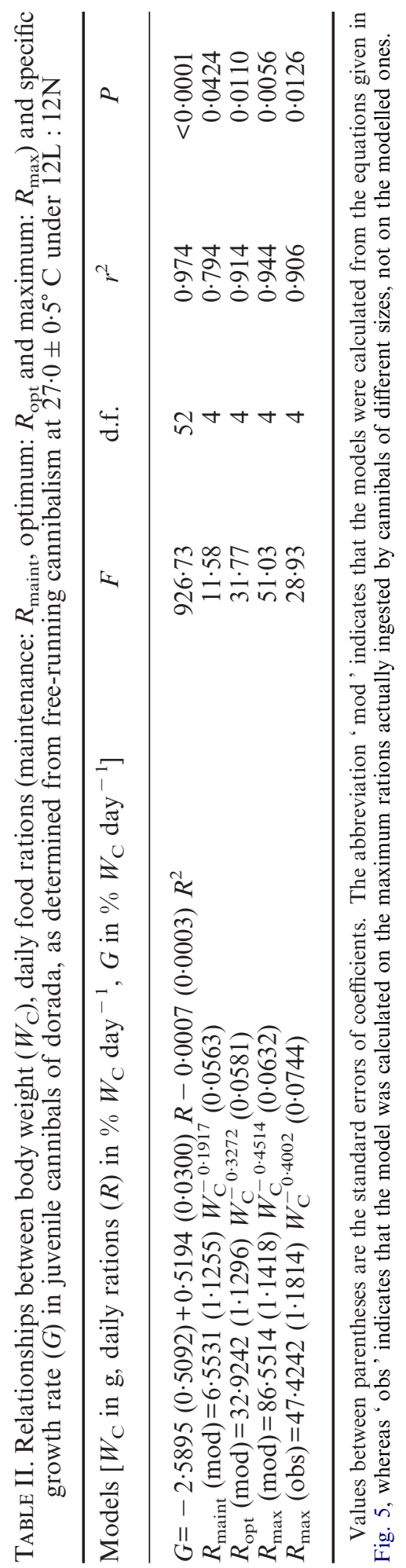



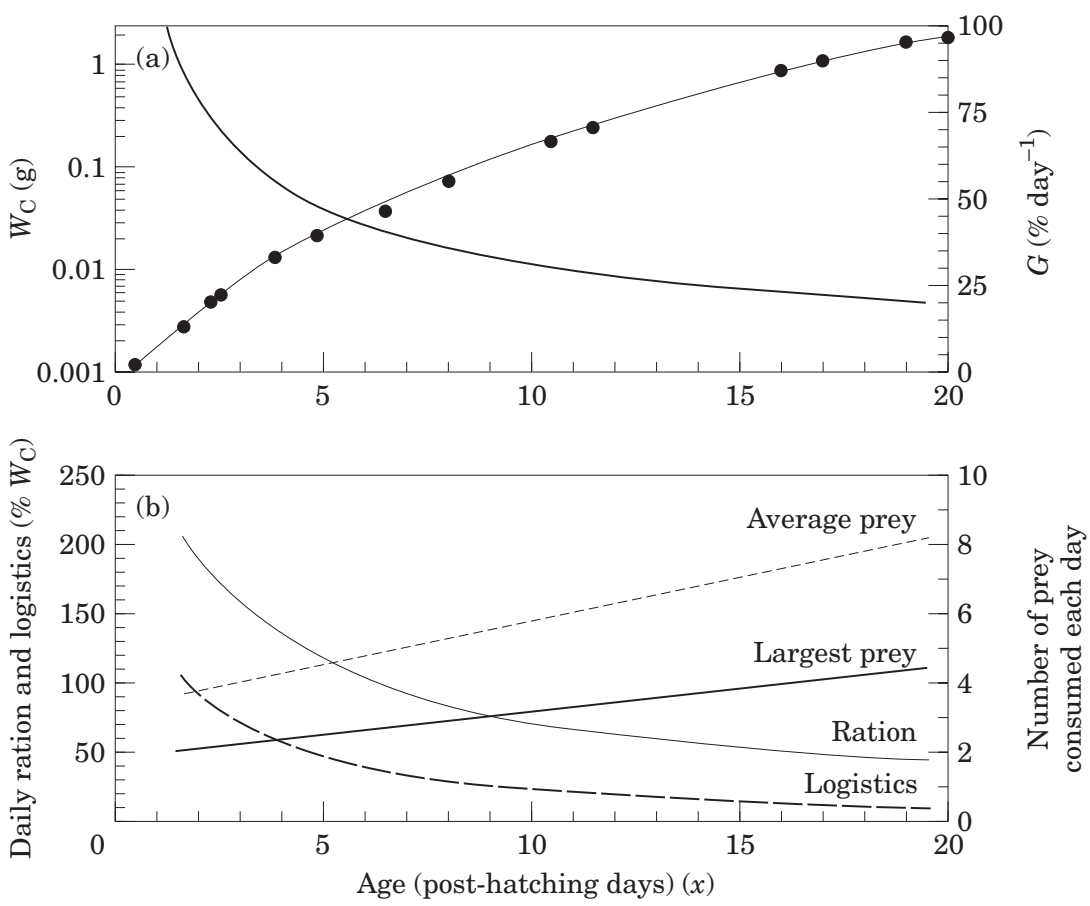

FIG. 6. Modelled impact of a cannibal dorada on siblings. The specific growth rate $(G)$ on graph (a) was modelled from frequent weighings $\left(G=140.70 x^{-0.64} ; r^{2}=0.991\right)$. Daily rations in (b) were deduced from $G$, using the growth model in Table II. The variation of the logistics of cannibalism with increasing age was obtained from the model illustrated in Fig. 3. The calculation of the minimum numbers of prey ingested each day by the cannibal assumes the cannibal consumed the largest possible prey. The calculation of the average number of prey assumes prey were averaging $c$. half of its logistics (derived from experiments on predation, Fig. 4).

\section{DISCUSSION}

\section{EARLY EMERGENCE OF CANNIBALISM}

The impact of cannibalism in dorada $\left(c .40 \% \mathrm{day}^{-1}\right)$ is the most intense ever documented in all fish species examined to date (Smith \& Reay, 1991; Hecht \& Pienaar, 1993; Baras, 1998). Similar or yet higher rates of cannibalism have been reported in some species, but exclusively in experimental situations with almost equivalent numbers of prey and cannibals (sharptooth catfish, Prinsloo et al., 1989; snakehead, Qin \& Fast, 1996). An attempt to relate the intensity of cannibalism in different fish species and its emergence during ontogeny, indicates that cannibalism in dorada is consistent with that in other predatory fish species (Fig. 7). Hence, cannibalism in dorada is not exceptionally intense in view of its early emergence during ontogeny. However, this early emergence $(21 \mathrm{~h}$ after hatching) is precisely exceptional, and probably constitutes the earliest emergence of cannibalism (and possibly piscivory) documented in fish. One may argue that intra-uterine cannibalism of eggs and young has been documented (sharks; Wourms et al., 1988) or suspected (e.g. coelacanth Latimeria chalumnae Smith, Wourms et al., 1980) in viviparous species, the embryos of which have 


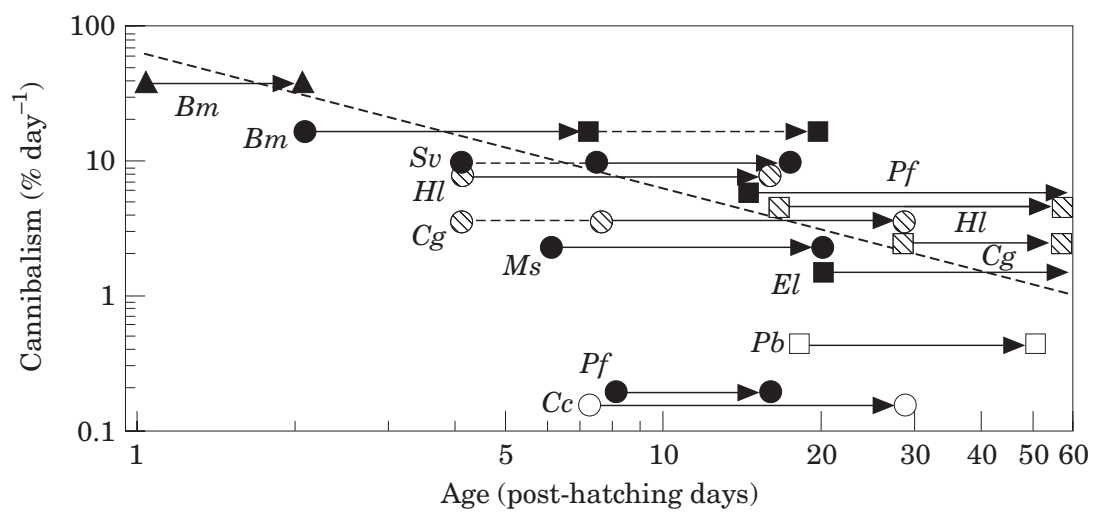

FIG. 7. Emergence and intensity of intra-cohort cannibalism in teleost fish, depending on predatory habits. The intensity of cannibalism is the mean over the period indicated by arrows and delimited by symbols. Triangles, circles and squares stand for embryos, larvae and juveniles, respectively. Closed symbols refer to fish species with a persistent predatory life style as adults, dashed symbols to omnivorous species, and open symbols to non-predatory species. Horizontal dotted lines indicate some variation between the moments of emergence for the same species in different environments. The bold oblique dotted line is a power relationship between the intensity of cannibalism and its emergence in predatory and omnivorous fish species $\left(r^{2}=0 \cdot 797, F=27 \cdot 52\right.$, $P<0 \cdot 001)$. Bm, Brycon moorei $\left(27^{\circ} \mathrm{C}\right.$, this study); Cc, Cyprinus carpio (28-29 ${ }^{\circ} \mathrm{C}$, van Damme et al., 1989); Cg, Clarias gariepinus (27-28 C; Hecht \& Appelbaum, 1988; E. Baras \& A. F. d'Almeida, unpubl. data); El, Esox lucius (12 ${ }^{\circ} \mathrm{C}$; Giles et al., 1986; Bry et al., 1992); Hl, Heterobranchus

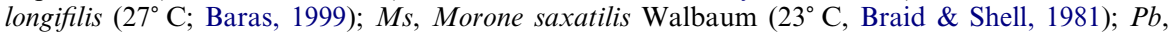
Piaractus brachypomus Cuvier (27 ${ }^{\circ} \mathrm{C}$; Baras \& Mélard, 1997); Pf, Perca fluviatilis $\left(20^{\circ} \mathrm{C}\right.$, E. Baras \& C. Mélard, unpubl. data); Sv, Stizostedion vitreum (18-22 ${ }^{\circ}$ C, Cuff, 1980; Loadman et al., 1986).

functional teeth. However, this happens quite late after fertilization, whereas cannibalism in dorada starts $<40 \mathrm{~h}$ after fertilization.

Several fish species are known to feed on exogenous food before their yolk sac is fully absorbed, but these have most rarely or never been found to exert cannibalism at this stage (walleye, Cuff, 1977, 1980; Moodie et al., 1989; sharptooth catfish, Hecht \& Appelbaum, 1988; perch, Brabrand, 1995; vundu catfish, Baras, 1999), contrary to dorada. Probably dorada can cannibalize each other at the embryonic stage because the early development of their oral teeth enables them to grasp and hold large elusive prey. The observation that embryos of dorada fed on small prey as early as $18 \mathrm{~h}$ after hatching, while cannibalism was coincidental with the full development of their oral teeth, supports this statement. The sequence of type Ia cannibalism, with prey being sucked in progressively up to the head, then regurgitated, is similar to that described in other species (e.g. Cuff, 1980; Hecht \& Appelbaum, 1988; Baras, 1999; E. Baras \& C. Mélard, unpubl. data). Cannibalism in chains has been reported far less frequently (Cuff, 1980; Woynárovitch \& Woynárovitch, 1991), and its occurrence is dependent apparently on the presence of oral teeth. Chains were never found to contain more than seven individuals, and rarely more than three, presumably because of increasing mechanical constraints in chains of increasing size. Adding to the original description by Cuff (1980), chains could enlarge either when another fish attacked a cannibal consuming a prey, or when a prey being currently ingested grasped another fish touching its teeth. 


\section{ADAPTIVE AND EVOLUTIONARY SIGNIFICANCE OF EARLY} CANNIBALISM

The reason why dorada evolved towards the production of perfect killers from the embryonic stage whereas most other species didn't or failed, is still uncertain. Because of the marked synchrony between heart rate, operculum and jaw movement, type Ia cannibalism at the embryonic stage can be viewed as a simple biting reflex, involving no prey selection at all. In a mono-specific, intra-cohort, context, prey selection would be rather pointless, in view of the marked synchronicity of hatching times and development of oral teeth, making all siblings potential prey or cannibals. As a corollary, hatching later than others may be a more serious penalty for dorada than for most other species investigated to date, and early cannibalism may have represented an evolutionary pressure on hatching synchronicity in this species.

With respect to fitness, early cannibalism in dorada permits elimination of competitors and potential predators, but imposes greater risks of being cannibalized while swimming erratically in the water column and encountering many other potential cannibals. Because cannibalism brings a substantial growth advantage, no doubt risk-takers (surviving cannibals) have an advantage over care-takers (non-cannibals) in the long run, since they will have greater chances of escaping the attacks of allochtonous predators and of accessing a wider range of prey, including the care-takers. However, in view of the huge losses to cannibalism during the first week of exogenous feeding, exclusive cannibalism in dorada would definitely turn to a nonevolutionary stable strategy. As a corollary, the early development of oral teeth and associated predation capacities would have been counter selected in environments where no alternative prey were available soon after dorada hatched.

As many South American freshwater species with high fecundity and low degree of parental care (seasonal strategists; Winemiller, 1989), dorada undertake long upstream migrations under receding waters during the second part of the dry season, and spawn soon after the onset of the rainy season (Goulding, 1980). Their eggs (which are slightly pelagic) and embryos, are displaced to downstream nurseries in the floodplain. By analogy with other South American species (Pavlov et al., 1995), this drift probably extends over hundreds of kilometres, and over several days. Here, dorada unable to feed within 4 days after hatching died of hunger, suggesting that embryos or larvae of dorada displaced by the floods probably have very little time to find food. In these circumstances, the early development of sharp oral teeth may represent a substantial advantage for grasping and holding occasional large prey, including larvae of other species spawning at the same period of the year. Considering the huge dispersal of larvae, the risk of consuming a sibling presumably is very low. Hence, we suggest that the evolution of early piscivory in dorada was promoted by the similarity between the life history strategies of seasonal strategists in South American assemblages, and chiefly by the marked synchronicity of spawning behaviour of these species at the onset of the rainy season and drift of eggs and larvae in the floodplain. 


\section{TRANSITIONS BETWEEN TYPES OF CANNIBALISM}

Contrary to most fish species, where incomplete cannibalism is a matter of gape width and height, embryos of dorada can ingest completely the head of prey of equivalent size in their buccal cavity, chiefly because of the exceptional depression of their lower jaw. During the first hours of exogenous feeding, the prey head is still blocked at the oesophagus and regurgitated (type Ia cannibalism). Later, the prey is ingested entirely into the stomach, then regurgitated partly, presumably because dorada cannot digest hard body parts at this developmental stage. Considering that fish exerting type Ib cannibalism ingest prey with slightly lower $W_{\mathrm{P}}: W_{\mathrm{C}}$ ratios than those exerting type Ia cannibalism, and that both types of cannibalism involve a long regurgitation process, the energetic advantage of type $\mathrm{Ib}$ over type Ia cannibalism is not obvious. However, the shift to type Ib cannibalism may enable the cannibal to limit the risks of being preyed on, at a time when numerous individuals still exert predation. Indeed, the erratic swimming consecutive to ingestion is much shorter (minutes instead of hours), and prey are no longer alive at the time they become regurgitated, reducing the probability that a chain tail from this side.

A similar interpretation applies to the transition from type I to type II cannibalism. Juvenile dorada with fully developed fins may have greater facilities than embryos or larvae to escape tail attacks by cannibals of close size, suggesting that type I cannibalism would be less profitable than type II cannibalism in juvenile dorada (see parallel in vundu, Baras, 1999). The transition from type II to type III cannibalism, when several fish take bites from a single prey, as do piranhas (Breder, 1927, in Smith \& Reay, 1991), can be accounted for by cannibals becoming increasingly limited in their choice of prey (see below), and no longer finding prey of appropriate size. Probably the head of prey was not consumed as there was a risk for the predators to ingest cutting tricuspid teeth. Despite type III cannibalism requiring no particular weight ratio between the cannibals and their prey, it vanished in older juveniles. This was coincident with the development of the adult colour pattern on the caudal peduncle. It cannot be excluded that this may act as a visual cue inhibiting cannibalism, just as has been demonstrated in cichlids (Zaret, 1977). However, this remains to be determined experimentally.

\section{LOGISTICS OF COMPLETE CANNIBALISM AND PREY SIZE SELECTIVITY}

In this series of experiments, the logistics of complete (type II) cannibalism were deduced from actual predation acts, not from measurements of morphological traits [usually the largest cross-sectional dimension (width or height) of mouth and head; e.g. Hecht \& Appelbaum, 1988; Brabrand, 1995; Baras, 1999]. However, dorada exerted incomplete cannibalism or starved when the remaining prey were above the modelled logistics, suggesting that these logistics were not underestimated. Conversely, recently Qin \& Fast (1996) provided evidence that morphological measures may underestimate the actual logistics of cannibalism, as they rarely take into account the elasticity of mouth parts. Compared with other fish species, the logistics of type II cannibalism in dorada have an extremely high initial value (c. $65-70 \%$ in 5-6-mg fish), probably because it is exerted first by larvae with unossified head skeleton and huge depression of the 
lower jaw, whereas it rarely starts before the juvenile stage in other fish species (Hecht \& Pienaar, 1993; Baras, 1998).

The logistics of type II cannibalism in dorada decreased steeply during the juvenile stage. A negative correlation between the logistics of predation and fish size usually reflects allometric changes in body proportions (i.e. slower growth of mouth size respective to body size). With few exceptions (e.g. catfishes; Hecht \& Appelbaum, 1988; Baras, 1999), these are frequent in juvenile fish (e.g. carp Cyprinus carpio L., van Damme et al., 1989; Atlantic cod, Otterå \& Folkvord, 1993; snakehead, Qin \& Fast, 1996). However, their slope is rarely as steep as in dorada, causing large juvenile dorada to exert cannibalism on smaller prey than in other species with initially lesser ingestion capacities (e.g. for 20-g fish: $4 \cdot 28 \%$ in dorada v. $9 \cdot 14 \%$ in Atlantic cod, c. $10 \%$ in sharptooth catfish; $13.33 \%$ in Eurasian perch; $16.67 \%$ in vundu catfish; and $22.29 \%$ in snakehead; recalculated from Otterå \& Folkvord, 1993; Hecht \& Appelbaum, 1988; Brabrand, 1995; Baras, 1999; Qin \& Fast, 1996, respectively). Among well provisioned dorada showing little depensatory growth, normally such a steep decrease of the ingestion capacity should cause complete cannibalism to end very early during ontogeny. Conversely, because the size-related decrease of the logistics of cannibalism in dorada exceeds the corresponding reduction of their food rations, the impact of individual cannibals would still increase slightly during their ontogeny, provided enough prey are available (Fig. 6).

Juvenile dorada rarely consume prey close to their logistics, and obviously they preferred the smallest prey available. The ingestion of the largest possible prey is a rare phenomenon in fish (Baras, 1999), and apparently is restricted to fish exerting ambush predation (e.g. pike, catfishes). In many fish species, there are excellent reasons for not selecting the largest possible prey. For example, in Eurasian perch consuming prey close to or exceeding slightly their logistics, any attempt to regurgitate a prey too large to be ingested into the stomach causes the spiny finrays of the prey to damage the digestive tract of the cannibal, or the cannibal to suffocate (Brabrand, 1995; Mélard et al., 1996). A similar consideration could be evoked here with respect to the large cutting teeth of dorada. Also, Amundsen et al. (1995) indicated that juvenile Arctic charr Salvelinus alpinus L., preyed on the smallest conspecifics available, and excluded systematically prey larger than $35 \%$ of their logistics $\left(W_{\mathrm{P}}: W_{\mathrm{C}}\right.$ ratio of $c .6 \%$, as defined from field studies by l'Abée-Lund et al., 1992). They proposed that the increase in the pursuit plus handling time of a large prey would exceed the benefit gained from the prey's higher energy content, especially since the fast-start performance and escape abilities of fish of increasing length increase in a non-linear way (Webb, 1978). The finding that some large prey escaped cannibalism despite the fact that they were small enough to be consumed by the cannibal, suggests that this interpretation applies to dorada also.

\section{APPLICATION TO AQUACULTURE}

The food ration of cannibal dorada exceeded those of most cannibalistic species examined to date, with fish $<0 \cdot 1 \mathrm{~g}$ being able to ingest as much as $130 \%$ of their body weight per day. Their net growth efficiency $(0 \cdot 73-0 \cdot 80)$, was also much higher than in most other fish species, and similar to those of adult rainbow trout Oncorhynchus mykiss Walbaum (0·70; Staples \& Nomura, 1976) 
or Nile tilapia Oreochromis niloticus L. (0·76; Mélard, 1986). The combination of high rations and high growth efficiency permitted an extremely fast growth (record body weights of $0 \cdot 19,7 \cdot 92$ and $26.84 \mathrm{~g}$ after 7,18 and 27 days of exogenous feeding, respectively; unpubl. results), and contributed to the sustained exercise of cannibalism until all potential prey were consumed. These traits make dorada a most interesting candidate for aquaculture in tropical countries, provided that cannibalism can be reduced drastically. The models of growth and logistics of cannibalism presented here, provide the bases for preserving larvae and juveniles from cannibalism by hand sorting, or by mechanical size grading on grids. However, usually mechanical size-grading is impractical in fish $<0 \cdot 1 \mathrm{~g}$, and it would be inefficient in dorada, since the logistics of cannibalism would still be as high as $26 \cdot 3 \%$, and losses to cannibalism may already have exceeded $90 \%$ of the initial stock by that time.

This indicates that absolute priority should be given to the reduction of early cannibalism at the embryonic and larval stages, essentially by improving the rearing conditions and provision of food during the early development. Because early cannibalism in dorada is chiefly a contact-and-consume behaviour, decreasing the stocking density could improve their survival. Similarly, their duoculture together with embryos or larvae of a less valuable species would reduce the probability that dorada attack siblings. These aspects are investigated in the second part of this study (Baras et al., 2000).

This study was part of E.U. contract CI1*-CT94-0032 (DG XII HSMU). The authors wish to thank Electrabel s.a. for supporting the fish culture programmes at the University of Liège. M. Y. J. Maxi and M. Ndao were granted fellowships by the Belgian C.U.D. during their stay in Belgium. Experiments were carried out in accordance with the Guidelines for the Use of Animals in Research published in Animal Behaviour 55, 251-257 (1998).

\section{References}

Amundsen, P.-A., Damsgard, B., Arnesen, A. M., Jobling, M. \& Jørgensen, E. H. (1995). Experimental evidence of cannibalism and prey specialization in Arctic charr, Salvelinus alpinus. Environmental Biology of Fishes 43, 285-293.

Baras, E. (1998). Biological bases of cannibalism in fish. Cahiers d'éthologie 18, 53-98 (in French, English abstract and captions).

Baras, E. (1999). Sibling cannibalism among juvenile vundu under controlled conditions. I. Cannibalistic behaviour, prey selection and prey size-selectivity. Journal of Fish Biology 54, 82-105.

Baras, E. \& Mélard, C. (1997). Growth-survival-cannibalism dynamics among larvae and juveniles of Pirapatinga (Piaractus brachypomus) at different stocking densities. In Proceedings of Martinique '97, Island Aquaculture and Tropical Aquaculture (Creswell, L. \& Harache, Y., eds), pp. 34-35. Oostende, Belgium: European Aquaculture Society.

Baras, E., Tissier, F., Philippart, J.- C. \& Mélard, C. (1999). Sibling cannibalism among juvenile vundu under controlled conditions. II. Effect of body weight and environmental variables on periodicity and the intensity of type II cannibalism. Journal of Fish Biology 54, 106-118.

Baras, E., Maxi, M. Y. J., Ndao, M. \& Mélard, C. (2000). Sibling cannibalism in dorada under experimental conditions. II. Effect of initial size heterogeneity, diet and light regime on early cannibalism. Journal of Fish Biology 57, 1021-1036. 
Brabrand, A. (1995). Intracohort cannibalism among larval stages of perch (Perca fluviatilis). Ecology of Freshwater Fish 4, 70-76.

Braid, M. R. \& Shell, E. W. (1981). Incidence of cannibalism among striped bass fry in an intensive culture system. Progressive Fish-Culturist 43, 210-212.

Breder, C. M. (1927). The fishes of the River Chucunaque drainage, eastern Panama. Bulletin of the American Museum of Natural History 57, 91-176.

Brett, J. R. (1979). Environmental factors and growth of fish. In Fish Physiology, Vol. VIII (Hoar, W. S., Randall, D. J. \& Brett, J. R., eds), pp. 599-675. London: Academic Press.

Bry, C. \& Gillet, C. (1980). Réduction du cannibalisme précoce chez le brochet (Esox lucius) par isolement des fratries. Bulletin Français de Pisciculture 277, 142-153.

Bry, C., Basset, E., Rognon, X. \& Bonamy, F. (1992). Analysis of sibling cannibalism among pike, Esox lucius, juveniles reared under semi-natural conditions. Environmental Biology of Fishes 35, 75-84.

Cuff, W. R. (1977). Initiation and control of cannibalism in larval walleyes. Progressive Fish-Culturist 39, 29-32.

Cuff, W. R. (1980). Behavioral aspects of cannibalism in larval walleye, Stizostedion vitreum. Canadian Journal of Zoology 58, 1504-1507.

Damme van, P., Appelbaum, S. \& Hecht, T. (1989). Sibling cannibalism in koi carp, Cyprinus carpio L., larvae and juveniles reared under controlled conditions. Journal of Fish Biology 34, 855-863.

Dong, Q. \& Polis, G. A. (1992). The dynamics of cannibalistic populations: a foraging perspective. In Cannibalism: Ecology and Evolution among diverse Taxa (Elgar, M. A. \& Crespi, B. J., eds), pp. 13-37. Oxford: Oxford Science Publications.

Folkvord, A. (1997). Ontogeny of cannibalism in larval and juvenile fishes with special emphasis on Atlantic cod. In Early Life History and Recruitment in Fish Populations (Chambers, R. C. \& Trippel, E. A., eds), pp. 251-278. London: Chapman \& Hall.

Giles, N., Wright, R. M. \& Nord, M. E. (1986). Cannibalism in pike fry, Esox lucius L.: some experiments with fry densities. Journal of Fish Biology 29, 107-113.

Goulding, M. (1980). The Fishes and the Forest. Explorations in Amazonian Natural History. Berkeley: University of California Press.

Hecht, T. \& Appelbaum, S. (1988). Observations on intraspecific aggression and coeval sibling cannibalism by larval and juvenile Clarias gariepinus (Clariidae: Pisces) under controlled conditions. Journal of Zoology 214, 21-44.

Hecht, T. \& Pienaar, A. G. (1993). A review of cannibalism and its implication in fish larviculture. Journal of the World Aquaculture Society 24, 246-261.

Jones, J. S. (1982). Of cannibals and kins. Nature 299, 202-203.

Katavic, I., Jug-Dujakovic, J. \& Glamuzina, B. (1989). Cannibalism as a factor affecting the survival of intensively cultured sea bass (Dicentrarchus labrax) fingerlings. Aquaculture 77, 135-143.

L'Abée-Lund, J. H., Langeland, A. \& Saegrov, H. (1992). Piscivory by brown trout Salmo trutta L. and Arctic charr Salvelinus alpinus (L.) in Norwegian lakes. Journal of Fish Biology 41, 91-101.

Loadman, N. L., Moodie, G. E. E. \& Mathias, J. A. (1986). Significance of cannibalism in larval walleye (Stizostedion vitreum). Canadian Journal of Fisheries and Aquatic Sciences 43, 613-618.

Mélard, C. (1986). Les bases biologiques de l'élevage intensif du tilapia du Nil. Cahiers d'Ethologie appliquée 6, 1-224.

Mélard, C., Baras, E., Mary, L. \& Kestemont, P. (1996). Relationships between growth, cannibalism and survival rate in intensively cultured larvae and alevins of perch (Perca fluviatilis). Annales Zoologici Fennici 33, 643-651.

Moodie, G. E. E., Loadman, N. L., Wiegand, M. D. \& Mathias, J. A. (1989). Influence of egg characteristics on survival, growth and feeding in larval walleye (Stizostedion vitreum). Canadian Journal of Fisheries and Aquatic Sciences 46, $516-521$. 
Otterå, H. \& Folkvord, A. (1993). Allometric growth in juvenile cod (Gadus morhua) and possible effects on cannibalism. Journal of Fish Biology 43, 643-645.

Pavlov, D. S., Nezdoliy, V. K., Urteaga, A.K. \& Sanches, O. R. (1995). Downstream migration of juvenile fishes in the rivers of Amazonian Peru. Journal of Ichthyology 35, 227-248.

Polis, G. A. (1981). The evolution and dynamic of intraspecific predation. Annual Reviews of Ecology and Systematics 12, 225-251.

Prinsloo, J. F., Schoonbee, H. J. \& Theron, J. (1989). The use of a red strain of the sharptooth catfish Clarias gariepinus (Burchell) in the evaluation of cannibalism amongst juveniles of this species. Water South Africa 15, 179-184.

Qin, J. \& Fast, A. W. (1996). Size and feed dependent cannibalism with juvenile snakehead Channa striatus. Aquaculture 144, 313-320.

Smith, C. \& Reay, P. (1991). Cannibalism in teleost fishes. Reviews in Fish Biology and Fisheries 1, 41-64.

Staples, D. J. \& Nomura, M. (1976). Influence of body size and food ration on the energy budget of rainbow trout Salmo gairdneri Richardson. Journal of Fish Biology 9, $29-43$.

Webb, P. W. (1978). Fast start performance and body form in seven species of teleost fish. Journal of Experimental Biology 74, 211-226.

Winemiller, K. O. (1989). Patterns of variation in life history among South American fishes in seasonal environments. Oecologia 81, 225-241.

Wourms, J. P., Stribling, M. D. \& Atz, J. W. (1980). Maternal-fetal nutrient relationships in the coelacanth, Latimeria. American Zoologist 20, 962.

Wourms, J. P., Grove, B. D. \& Lombardi, J. (1988). The maternal-embryonic relationship in viviparous fishes. In Fish Physiology, Vol. XI, Part B (Hoar, W. S. \& Randall, D. J., eds), pp. 1-134. London: Academic Press.

Woynárovitch, E. \& Woynárovitch, A. (1991). Rearing techniques of some predator fish fry and fingerlings. In Larvi'91 (Lavens, P., Sorgeloos, P., Jaspers, E. \& Ollevier, F., eds), pp. 275-276. Gent: European Aquaculture Society.

Zaret, T. M. (1977). Inhibition of cannibalism in Cichla ocellaris and hypothesis of predator mimicry among South American fishes. Evolution 31, 421-437. 